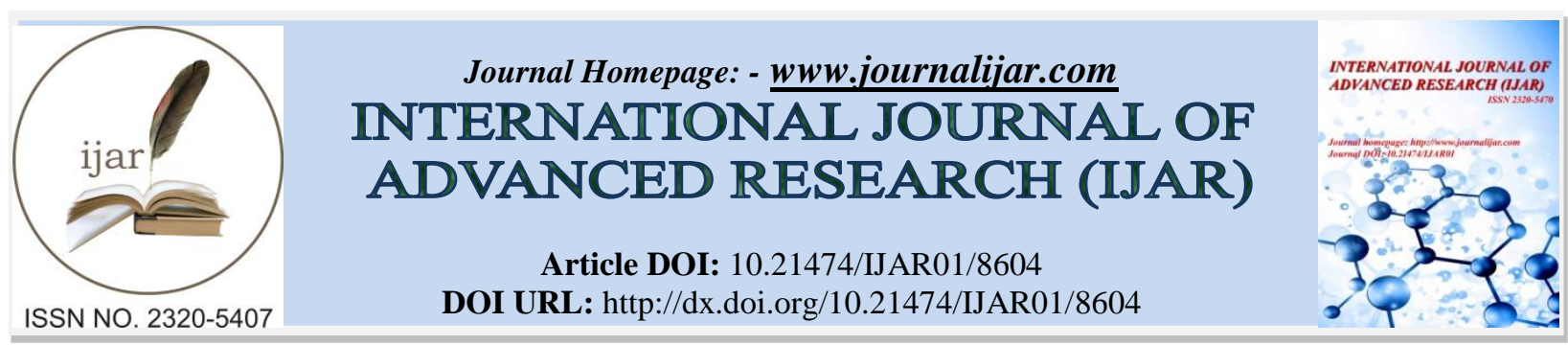

RESEARCH ARTICLE

\title{
VARYING THE LEVEL OF CHILI CONCENTRATION FOR QUALITY IMPROVEMENT OF VACUUM-FRIED TAHONG (Perna viridis L.) CHIPS.
}

\author{
Karen Luz Teves. \\ Associate Professor, Department of Agricultural Education and Extension, Visayas State University, Visca, Baybay \\ City, Leyte Philippines.
}

\section{Manuscript Info}

\section{Manuscript History}

Received: 04 January 2018

Final Accepted: 06 February 2019

Published: March 2019

Key words:-

chili concentration, vacuum-fried tahong

chips, quality improvement
Abstract

The study was carried out to develop a spicy-flavored vacuum-fried tahong chips using different levels of chili. Specifically, the study developed process flow for vacuum-fried tahong chips, determined the effects of chili on the sensory properties of the product an determined the production cost of the product. Findings showed that increasing the level of chili used in processing the product by $1 \%$ can significantly affect the taste and general acceptability of the product but not the color, crispness, flavor and texture of the product. The use of $4 \%$ chili obtains higher product acceptability compared to using only $3 \%$. About Php51.00 is required to produce 50 grams of spicyflavored vacuum fried tahong chips. Other variables such as level of sugar and vacuum frying time should be looked into for future studies.

Copy Right, IJAR, 2019,. All rights reserved.

\section{Introduction:-}

The Asian green mussel (Perna viridis L.), also known as the Philippine green bay mussel, locally known as "tahong" is a bivalve belonging to the family Mytilidae. The mussel is economically important in several countries where it is harvested for food; however it is known to harbor toxins, which are hazardous to human health. There are three species of mussel in the Philippines which are used as food: the green bay mussel Perna viridis the brown mussel Modiolus metcalfei and M.philippinarum. Tahong as it is locally known is the only species of mussel farmed commercially in the Philippines.

Mussels are highly perishable products that require intensive care if the quality is to be maintained for sometimes after harvesting. There are many forms of postprocessing of mussel as practiced in many parts of the world. Canned, frozen, marinated, smoked, dried, processed into powder, and pickled (CMFRI, 1980). In the Philippines, the mussel is processed into crackers or bottled like the adobong tahong (NSCB, 2006). Vacuum frying is an excellent alternative to conventional frying which offers significant benefits such as the improvement of fried product safety and quality and reduced oil oxidation because of the low-temperature processing (Garayo and Moreira, 2002). Vacuum frying is 
a deep-fat frying process, which is carried out in a closed system, below the atmospheric pressure, substantially reducing the boiling point of water and, hence, the frying temperature. The low frying temperatures and minimal exposure to oxygen are responsible for most of the benefits of the fried products, which include nutrient preservation (da Silva and Moreira, 2008), oil quality protection (Shyu, Hau and Hwang, 1998) and reduction in toxic compound generation (Granda, Moreira, and Tichy, 2004).

Enhancement of vacuum fried tahong can be done by adding chili to make the final product flavorful. The roles of the chili in tahong products is to mask the off odor of the tahong and add spicy flavor to the finished product. In medicinal terms, chili was earlier utilized as an herbal plant to ease arthritis, rheumatism, dyspepsia, flatulence and toothache (Nagpala, 2007). Correct concentration of chili should be determined to be able to get the optimum sensory acceptability. Hence, this study was conducted.

\section{Statement of the Problem}

In general, the study developed a spicy-flavored vacuum-fried tahong chips using different levels of chili. The specific objectives were as follows:

1. Developed process flow for vacuum-fried tahong chips.

2. Determined the effects of chili on the sensory properties of vacuum fried tahong as affected by the different levels of chili.

3. Determined the production cost of the product.

\section{Materials and Methods \\ Procurement of Raw Materials}

Tahong were purchased at Baybay City Public Market. Other ingredients were purchased at any available Super market in Baybay City and Visca Market, Baybay City.

\section{Preliminary Study}

A preliminary study was done to develop a process flow to process the spicy-flavored vacuum fried tahong chips from raw material preparation to steam blanching of tahong to properly remove the tahong meat from their shells, then blanching of tahong meat with the flavorants consisting of water, sugar, salt and chopped chili. Two vacuum frying temperatures were tried; $100^{\circ} \mathrm{C}$ and $90^{\circ} \mathrm{C}$ in order to determine which temperature can produce crispier tahong chips. In the end, a process flow for the product was finalized as shown in Figure 1.

\section{Product Preparation}

Based on the developed process flow, tahong were washed thoroughly and sanitized with $20 \mathrm{ppm}$ chlorine concentration. The shells were steam blanched for few minutes to open the shell and then the tahong meat were removed from the shell, then drained to remove excess water. Tahong were blanched with flavorants consisting of different levels of chili for 2 minutes. The partially cooked flavored tahong were packed and frozen overnight. On the following day, the frozen flavored tahong were vacuum fried at $90^{\circ} \mathrm{C}$ for 40 minutes using palm oil.

\section{Experimental Design}

The study used Complete Randomized Design using two treatments in determining the effects of levels of chili. Two formulations of spicy-flavored vacuum fried tahong chips was used in this study (3\% and $4 \%$ chili w/v).

\section{Sensory Evaluation}

Sensory evaluation of the different treatments were carried out using a 30 evaluators composed of BS Food Technology students and DFST staff. Samples were randomly coded with three-digit number and the panelist were requested to evaluate the spicy-flavored vacuum fried tahong chips according to their taste, flavor, color, texture, crispness using the 5-point descriptive quality scoring and general acceptability using the 9-point Hedonic scale (Mabesa, 1986).

\section{Statistical Analysis}

The experiment was arranged using Completely Randomized Design (CRD) with three replicates. Treatments were subjected to ANOVA. For the descriptive data, frequency count was used to describe the product treatment. 


\section{Production cost}

The prevailing prices of the ingredients used and other expenses incurred like labor, electricity and other utilities was used as basis in determining the production cost. Break-even price (BEP) was computed following the formula below:

$$
\mathrm{BEP}=\frac{\text { Total Production } \operatorname{Cost}(\mathrm{PhP})}{\text { Total Yield }(g)}
$$

\section{Results and Discussion}

\section{Process flow of the product}

Based on the preliminary study done, a process flow chart was developed in processing spicy-flavored vacuum fried tahong chips. From raw material preparation such as washing, chlorinating, to steam blanching of tahong for removal of tahong meat from their shells, then quick blanching of tahong meat in flavorants, draining, overnight freezing to vacuum frying. In order to determine which temperature can produce a crispier tahong chips, two vacuum frying temperatures were tried; $90^{\circ} \mathrm{C}$ and $100^{\circ} \mathrm{C}$. Of the two vacuum frying temperatures tried; $100^{\circ} \mathrm{C}$ and $90^{\circ} \mathrm{C}$ respectively, at $90^{\circ} \mathrm{C}$ for 40 min vacuum frying, crispy tahong chips were produced. Using $100^{\circ} \mathrm{C}$ vacuum frying temperature quickly resulted to overfried tahong chips. In the end, a process flow for the product was finalized as shown in Figure 1.

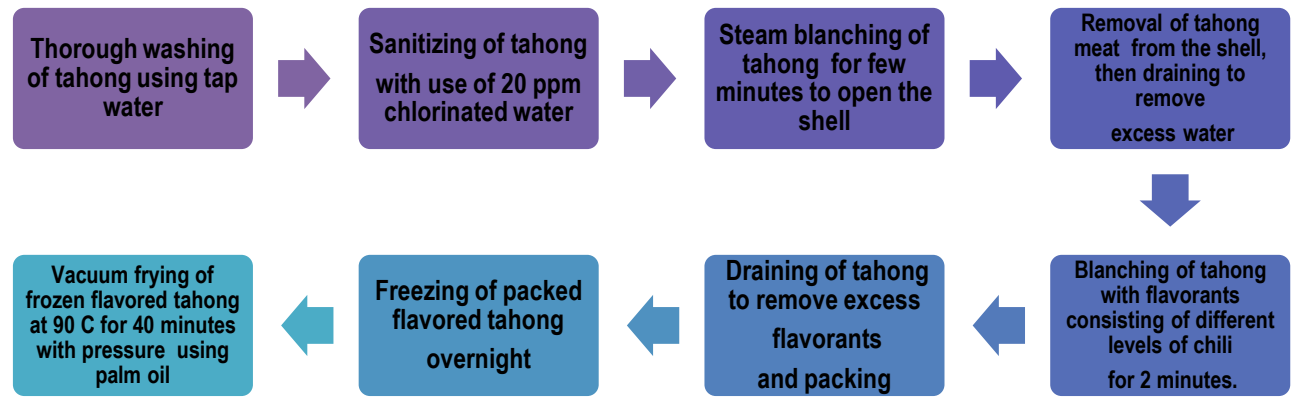

Figure 1:- Process flow of Spicy-Flavored Vacuum Fried Tahong Chips

\section{Sensory Evaluation}

The sample products of spicy-flavored vacuum fried tahong chips using two levels of chili are shown in figure 2 .

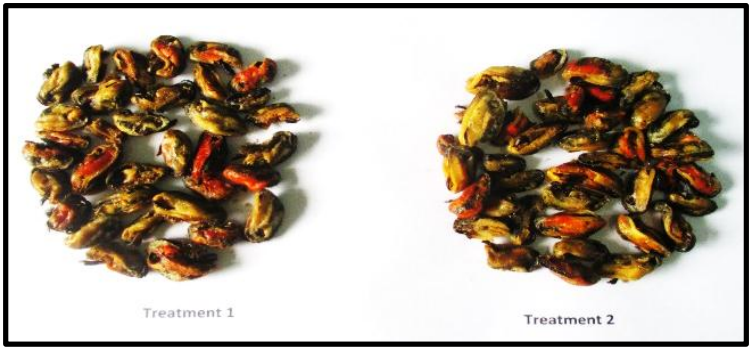

Figure 2:- Physical appearance of developed spicy-flavored vacuum fried tahong chips using two levels of chili.

The sensory qualities of spicy-flavored vacuum fried tahong chips from two levels of chili such as taste, flavor, color, texture, crispness and general acceptability were investigated to determine the products description and acceptability as afftected by chili concentration. Table 2 presents the analysis of variance of the various sensory parameters. The ANOVA results showed that taste and general acceptability exhibited significant difference between treatment 1 and treatment 2 . The taste and general acceptability showed highly significant difference (significant at $1 \%$ alpha level).

This significant difference in terms of taste and general acceptability only shows that even at $1 \%$ slight difference on the levels of chili significantly affects the taste of the vacuum fried tahong chips and general acceptability of the 
product as well. Color, crispness, flavor and texture were not affected by the varying levels of chili. Shown in Table 3 is the quality description and mean acceptability ratings for the taste, flavor, color, texture and crispness of vacuum fried tahong chips using two levels of chili.

As shown in Table 3, the taste description of vacuum fried tahong chips ranged from moderately spicy to spicy. Changes in the taste of the products are expected to be caused by the increased level of chili. The chili levels has nothing to do with the flavor, color, texture and crispness of the products. Taste acceptability rating of the product ranged from 7.1 to 7.8 with an overall response mean of 7.45 which corresponds to "like moderately". The flavor, color, texture and crispness descriptions of the products from both treatments are moderately spicy tahong flavor, dark brown in color, crispy with moderately soft texture. Mean acceptability ratings of flavor (7.3), color (7.15), texture (7.05) and crispness (7.35) which all corresponds to "like moderately".

Table 3:- Quality description and mean acceptability ratings for taste, flavor, color, texture and crispness of spicyflavored vacuum fried tahong chips using two levels of chili

\begin{tabular}{|c|c|c|l|c|c|}
\hline Attribute & Treatment & \% Chili & \multicolumn{1}{|c|}{ Description } & Frequency (\%) & $\begin{array}{c}\text { Acceptability } \\
\text { Rating }\end{array}$ \\
\hline \multirow{2}{*}{ Taste } & 1 & 3 & Moderately spicy & 43.3 & 7.1 \\
\cline { 2 - 6 } & 2 & 4 & Very spicy & 40.0 & 7.8 \\
\hline \multirow{2}{*}{ Flavor } & 1 & 3 & $\begin{array}{l}\text { Moderately spicy tahong } \\
\text { flavor }\end{array}$ & 36.7 & 7.3 \\
\cline { 2 - 6 } & 2 & 4 & $\begin{array}{l}\text { Moderately spicy tahong } \\
\text { flavor }\end{array}$ & 36.7 & 7.3 \\
\hline Color & 1 & 3 & Dark brown & 36.7 & 7.3 \\
\cline { 2 - 6 } & 2 & 4 & Dark brown & 33.3 & 7.0 \\
\hline Texture & 1 & 3 & Moderately soft & 40.0 & 7.0 \\
\hline Crispness & 2 & 4 & Moderately soft & 40.0 & 7.5 \\
\cline { 2 - 6 } & 2 & 3 & Crispy & 40.0 & 7.2 \\
\hline
\end{tabular}

\section{General Acceptability}

Found in Table 4 is the mean acceptability ratings for general acceptability of spicy flavored vacuum fried tahong chips as affected by the chili level. The acceptability ratings of the product ranged from 5.7 to 8.1 with an overall mean of 6.9 which corresponds to "like moderately" under the 9-point Hedonic scale. Treatment 2 using $4 \%$ chili got higher acceptability rating of 8.1 corresponding to "like very much" On the other hand, Treatment 1 using only $3 \%$ chili got acceptability rating of 5.7 which corresponds to "like slightly". The higher level of chili in the product made the panelists liked the product very much.

\section{Production Cost}

Production cost sums up the total cost of raw materials, electricity and utilities incurred in producing spicy-flavored vacuum fried tahong chips. The cost of producing 50 grams of vacuum fried tahong chips is shown in Table 4 . The summary of production cost of spicy-flavored vacuum fried tahong chips ranged from Php 50.00 to Php 52.00 with an overall mean of Php 51.00 per 50 grams.

Table 4:- Summary on the analysis of variance on sensory parameters of spicy flavored vacuum fried tahong chips using two levels of chili

\begin{tabular}{|c|c|c|c|c|c|c|}
\hline Attributes & & $\begin{array}{c}\text { Sum of } \\
\text { Squares }\end{array}$ & df & $\begin{array}{c}\text { Mean } \\
\text { Square }\end{array}$ & $\mathbf{F}$ & Sig. \\
\hline \multirow[t]{3}{*}{ Taste } & Between Groups & 96.267 & 1 & 96.267 & 38.864 & .000 \\
\hline & Within Groups & 143.667 & 58 & 2.477 & & \\
\hline & Total & 239.933 & 59 & & & \\
\hline \multirow[t]{3}{*}{ Flavor } & Between Groups & .267 & 1 & .267 & .243 & .624 \\
\hline & Within Groups & 63.667 & 58 & 1.098 & & \\
\hline & Total & 63.933 & 59 & & & \\
\hline
\end{tabular}




\begin{tabular}{|c|c|c|c|c|c|c|}
\hline \multirow[t]{3}{*}{ Color } & Between Groups & .067 & 1 & .067 & .207 & .651 \\
\hline & Within Groups & 18.667 & 58 & .322 & & \\
\hline & Total & 18.733 & 59 & & & \\
\hline \multirow[t]{3}{*}{ Texture } & Between Groups & 2.400 & 1 & 2.400 & 1.699 & .198 \\
\hline & Within Groups & 81.933 & 58 & 1.413 & & \\
\hline & Total & 84.333 & 59 & & & \\
\hline \multirow[t]{3}{*}{ crispiness } & Between Groups & .017 & 1 & .017 & .018 & .894 \\
\hline & Within Groups & 54.167 & 58 & .934 & & \\
\hline & Total & 54.183 & 59 & & & \\
\hline \multirow{3}{*}{$\begin{array}{l}\text { General } \\
\text { acceptability }\end{array}$} & Between Groups & 86.400 & 1 & 86.400 & 101.578 & .000 \\
\hline & Within Groups & 49.333 & 58 & .851 & & \\
\hline & Total & 135.733 & 59 & & & \\
\hline
\end{tabular}

Table 5:- Summary of production cost of spicy-flavored vacuum fried tahong chips

\begin{tabular}{|c|c|c|}
\hline Treatment & \% Chili & Cost of Production (Php) \\
\hline 1 & 3 & 50.00 \\
\hline 2 & 4 & 52.00 \\
\hline
\end{tabular}

\section{Conclusions:-}

The following conclusions were drawn based on the results of the study;

1. Increasing the level of chili used in processing the product by $1 \%$ can significantly affect the taste and general acceptability of the product.

2. The $1 \%$ increase in the level of chili used cannot affect the color, crispness, flavor and texture of the product.

3. The use of $4 \%$ chili obtains higher product acceptability compared to using only $3 \%$.

4. About Php51.00 is required to produce 50 grams of spicy-flavored vacuum fried tahong chips.

\section{Recommendations:-}

The following recommendations are suggested for future studies;

1. Look into other variables such as level of sugar and vacuum frying time.

2. Packaging and storage studies of the product.

3. Shelf-life determination of the product.

\section{References:-}

1. Agard J., Kishore R., and B. Bayne. 1992. Perna viridis (Linnaeus, 1758): First record of the Indo-Pacific green mussel (Mollusca: Bivalvia) In the Caribbean. Caribbean Marine Studies 3:59-60.

2. Granda, R. G. Moreira, and S. E. Tichy. 2004. "Reduction of acrylamide formation in potato chips by lowtemperature vacuum frying," Journal of Food Science, vol. 69, no. 8, pp. E405-E411

3. Garayo, J. and R. Moreira. 2002. "Vacuum frying of potato chips," Journal of Food

4. Engineering, vol. 55, no. 2, pp. 181-191

5. Mabesa, L. 1986. Sensory Evaluation of Foods: Principles and Methods. University of the Philippines at Los Baños College, Laguna

6. Moreira R. 2010. "Frying: Vacuum". Encyclopedia of Agricultural, Food, and Biological Engineering, Second ed. 1.1 (2010): 693-696.

7. Nagpala, E. 2007. A fresh look at siling labuyo. BAR Chronicle 8(10). Retrieved 2009-10-22

8. P. F. da Silva and R. G. Moreira. 2008. "Vacuum frying of high-quality fruit and vegetable-based snacks," LWT_Food Science and Technology, vol. 41, no. 10, pp. 1758-1767

9. Sitoy, H., Young, A. and M. Tabbu. 1993. Raft culture of Mussels. SEAFDEC/AQD Institutional Repository (SAIR) Manual. ISSN - 0115-5369

10. S.-L. Shyu, L.-B. Hau, and L. S. Hwang, "Effect of vacuum frying on the oxidative stability of oils," Journal of the American Oil Chemists' Society, vol. 75, no. 10, pp. 1393-1398, 1998 